\title{
PERSEA INDICA AS A NATURAL SOURCE OF THE INSECTICIDE RYANODOL
}

\author{
azucena González-Coloma, Ramundo Cagrera, † Ana R. Socorro Monzón $\ddagger$ and Braulio M. Fraga
}

*Instituto de Productos Naturales y Agrobiología, CSIC, Ave. Astrofisico F. Sánchez 2, 38206 La Laguna, Tenerifé, Spain; †UDI Fitopatologia, Departamento de Biología Vegetal, Universidad de La Laguna, Tenerife, Spain; łCentro de Investigación y Tecnologia Agraria, Apdo. 60, La Laguna, Tenerife, Spain

(Received in revised form 26 January 1993)

Key Word Index-Persea indica; Lauraceae; insecticide; diterpene; ryanodol; nitrogen; phenolics; variation.

\begin{abstract}
Since Persea indica is a natural source of the insecticidal diterpene ryanodol, 20 mature naturally growing trees from two locations were surveyed for their content in this compound, as well as for nitrogen, water and total phenolics. The foliar ryanodol content of the trees did not show seasonal variations and did not correlate with the nitrogen, water or phenolic content. This diterpene did vary however, among the individual trees and was found to accurnulate in the stems. The results are discussed in the light of the prospects for using this plant as a source of natural pesticide.
\end{abstract}

\section{INTRODLCTION}

The search for botanical insecticides is of current interest because the use of the synthetic ones has led to the development of pest resistance. Furthermore, many botanical pesticides have the advantage of providing nove! modes of action that reduce the risk of cross-resistance.

The tree Persea indica (Lauraceae), an endemic species of the Canarian laurel forest, contains the toxic diterpene ryanodol (1) [ $]$ ], a known insecticide with the potential for use as a pest control agent [2-5]. Compound 1 and its didehydro analogue show remarkable selectivity in their toxicity to arthropods including Musca domestica, Periplaneta americana and Procambarus clarkii, when compared with their toxicity to mice $[2,3]$. At present the complexity of the ryanoid ring system precludes access to synthetic congeners of 1 which could potentially serve as selective insecticides acting on a non-neuronal target [3]. Therefore, the variation and distribution of $\mathbf{I}$ in $\boldsymbol{P}$. indica, its only known natural source [1], are important factors when considering the potential practical uses of this plant as a source of this compound.

To date, nothing has been reported about the above mentioned variations in the phytochemistry of $P$. indica. In this study, we report on the quantitative variation of foliar 1 content, as well as its distribution between leaves and stems during two growth periods, and an intermediate date.

Since plant phenols are also carbon-based secondary metabolites with defensive properties, act as plant growth

* Author to whom correspondence should be addressed at: Centro de Investigaciones, Biológicas, CSIC, Velázquez 144, 28006 Madrid, Spain regulators $[6,7]$ and their concentration can be affected by nutritional factors $[8-11]$, we studied the variation in phenolic content of $P$. indica along with its nutritional status (nitrogen and water content) to determine if there was any correlation between these parameters and the 1 content.

\section{RESULTS AND DISCLSSION}

The ANOVA analysis of the data classified according to the different sources of variation (group, date and individual tree) showed that the two $P$. indica groups surveyed varied in their foliar nitrogen content, group 1 showing higher values than those of group 2 (Table 1). Classification of the data by collection date revealed that only the water and total phenolic content showed significant seasonal variation (Table 1), while the nitrogen and 1 content varied with the individual trees (Table 1, Fig. 1).

To determine if there was any association between the different variables measured, we conducted overall Spearman rank correlations among them. This analysis showed two positive correlation coefficients, one between water and nitrogen $(\rho=0.2, P=0.09)$ and another between

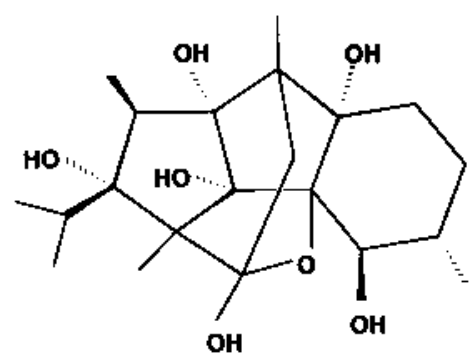


Table I. Mean values and stanclard errors of foliar \% nitrogen (N), $\mathrm{mg} \mathrm{g}^{-1}$ dry wt $\mathbf{l}(\mathrm{R}), \%$ water $(\mathrm{W})$ and $\mathrm{mg} \mathrm{g}^{-1}$ dry wt phenolic content $(\mathrm{P})$ of $P$, indica classified by group of origin or date of collection

\begin{tabular}{llllll}
\hline Factor & & $\mathrm{N}$ & $\mathrm{R}$ & $\mathrm{W}$ & $\mathrm{P}$ \\
\hline Group & 1 & $1.55(0.03)$ & $0.50(0.05)$ & $63.93(0.70)$ & $35.60(2.90)$ \\
& 2 & $1.25(0.04)$ & $0.40(0.04)$ & $65.57(0.56)$ & $40.09(2.85)$ \\
\multirow{4}{*}{ Date } & $P(n)^{*}$ & $<0.001(100)$ & $\mathrm{ns}(100)$ & $\mathrm{ns}(80)$ & $\mathrm{ns}(80)$ \\
& $4 / 89$ & $1.34(0.06)$ & $0.47(0.06)$ & $61.25(0.54)$ & $23.69(1.96)$ \\
& $7 / 89$ & $1.44(0.06)$ & $0.44(0.06)$ & $66.42(0.83)$ & $37.72(4.35)$ \\
& $10 / 89$ & $1.37(0.06)$ & $0.48(0.08)$ & $68.68(0.60)$ & $39.11(2.65)$ \\
& $4 / 90$ & $1.39(0.05)$ & $0.35(0.04)$ & $63.09(0.60)$ & $49.55(4.48)$ \\
& $P(n)^{*}$ & ns (100) & $\pi s(100)$ & $<0.001(80)$ & $<0.0001$ \\
Treet & $P(n)^{*}$ & $<0.001(100)$ & $<0.05(100)$ & ns $(80)$ & ns $(80)$ \\
\hline
\end{tabular}

"Probability level of Kruskall-Wallis one-way ANOVA by ranks (ns $=P \leqslant 0.05$ ) and simple size $(n)$ for the dala classified according to the different sources of variation.

t The average values and standard errors of each individual tree are in Fig. 1.

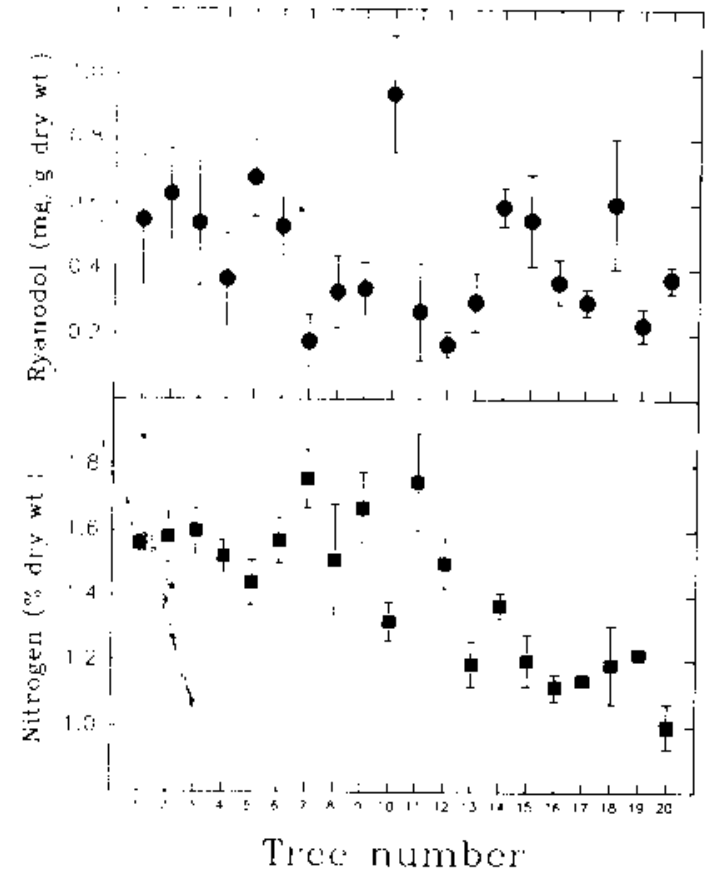

Fig. 1. Foliar $I$ and nitrogen content of individual $P$, indica trees. (jroup 1 includes trees number $1-10$ and group 2 includes tres number 1120 . Vertical bars represent \pm 1 s.c. $(n=5)$.

water and phenolic content $(\rho=0.16, P=0.21)$. The test also showed a negative coefficient between total phenolics and nitrogen content $(\rho=-0.20, P=0.21)$. None of these associations were statistically significant, bowever $(P>0$, 05. Table 2), indicating that the parameters measured wcre independent variables.

Table 3 shows the different allocation patterns of $\mathbf{1}$, nitrogen and phenolics measured for the leaves and stems of five selected $P$. indica trees. The leaves accumulated 2.05 and 2.62 times more nitrogen and phenolics, respectively, than the stems, while this ratio was 0.24 for 1 .
Table 2. Spearman Rank correlation coefficients $(\rho)$, sample sizes $(n)$ and probability levels $(P)$ of the correlations conducted among the following $P$. indica foliar variables: $\mathrm{N}$, nitrogen content ( $\%$ dry $w 1) ; W$, water content $(\%$ dry wt); $P$, phenolics ( $\mathrm{mg} \mathrm{g}^{-1} \mathrm{dry}$ wt) and $R, 1$ content (mg g ${ }^{1}$ dry wt)

\begin{tabular}{|c|c|c|c|}
\hline & $\mathbf{w}$ & $\mathrm{P}$ & $\mathbf{R}$ \\
\hline $\mathrm{N}$ & $\begin{array}{l}\rho=0.2 \\
n=(89) \\
P=0.09\end{array}$ & $\begin{array}{l}\rho=-0.2 \\
n=(89) \\
P=0.09\end{array}$ & $\begin{array}{l}\rho=-0.01 \\
n=\{89\} \\
P=0.88\end{array}$ \\
\hline w & & $\begin{array}{l}\rho=0.16 \\
n=(77) \\
P=0.21\end{array}$ & $\begin{array}{l}\rho=0.06 \\
n=(77) \\
P=0.63\end{array}$ \\
\hline $\mathbf{P}$ & & & $\begin{array}{l}\rho=0.062 \\
n=(76) \\
P=0.60\end{array}$ \\
\hline
\end{tabular}

First we wanted to know how much the ryanodol (1) content of $P$. indica varied and what relationship it had (if any) with the total phenolics and the nutrient content of the tree.

The foliar 1 content of $P$. indic $a$ did not vary with either the differences in nutrient content (different $\mathrm{N}$ content between groups 1 and 2) or the season. On the other hand, it showed individual variation that could be the result of genotypic differences. It has been previously shown that tree species and individual trees are unique and highly variable in terms of the temporal and spatial distribution of leaf characteristics [12-18] although the degree of genetic control vs the effects of environmental influence on these processes requires further investigation. On the contrary, the temporal variation in total phenolics of $P$. indica leaves indicated that the accumulation of these secondary metabolites is probably under environmental control. Many environmental factors (such as light) may 
Table 3. Mean values \pm standard error of nitrogen, 1 and phenolic content of $P$. indica leaves. their stems, and their ratios $(n=5)$

\begin{tabular}{|c|c|c|c|}
\hline \multirow[t]{2}{*}{ Variable } & \multicolumn{2}{|c|}{ Average values } & \multirow{2}{*}{$\begin{array}{l}\text { Averaged ratio } \\
\text { Leaves:Stems }\end{array}$} \\
\hline & Leaves & Stems & \\
\hline Nitrogen $(\%)$ & $1.85 \pm 0.08$ & $0.90 \pm 0.04$ & $2.05 \pm 0.05$ \\
\hline Ryanodol (mg g ${ }^{-1}$ dry wt) & $0.41 \pm 0.09$ & $1.74 \pm 0.39$ & $0.24 \pm 0.03$ \\
\hline Phenolics ( $\mathrm{mg} \mathrm{g} \mathrm{g}^{-1}$ dry wt) & $44.63 \pm 6.43$ & $17.03 \pm 3.30$ & $2.62 \pm 0.83$ \\
\hline
\end{tabular}

influence the activity of phenylalanine ammonia-lyase (PAL), a key enzyme in the phenolic biosynthetic pathway [19].

Regarding the nutrient content of the foliage, we observed that the amount of water changed with the season, but within a narrow range of variation (61.3-68.7\%), which indicated that water availability was not a limiting factor during this study, while the nitrogen levels varied with site (groups 1 and 2) and individual trees probably as a result of availability variations (soil nitrogen content data will be necessary to prove this hypothesis).

The $P$. indica foliar cohtent in I did not correlate with the phenolic content. This was in accordance with the supposition of different accumulation controls for 1 and phenolics (tree-dependent for 1 and environmental for phenolics). Neither the nitrogen nor the water content of the plant were associated with the accumulation of $\mathbf{1}$. However, nitrogen fertilization of $P$. indica seedlings increased their growth rate (unpublished results), resulting in higher biomass yields and thus in larger amounts of ryanodol-extractable material.

The second part of this project involved the study of the allocation patterns of 1 , nitrogen and phenolics between paired samples of leaves and stems, since previously synthesized secondary metabolites may be stored for use when and where their biosynthesis is constrained [20]. The stems preferentially accumulated the diterpene. Few reports have been published regarding the accumulation pattern of diterpenes in plants, but it varied with the plant species. For example, the tree Ginkgo biloba concentrated most of its diterpene content in the adult leaves [21]. On the contrary, the nitrogen and phenolic content was greater in the leaves than in the stems of $P$. indica, in accordance with the general trend observed for evergreen plants [20].

According to our results, individual $P$. indica trees with high 1 content should be selected to harvest their stems and also for future reproduction, regardless of the location or season, since the individual variation seemed to be the most important factor affecting the diterpene levels. Harvesting the stems of $P$. indica for 1 has a disadvantage when compared with the foliage because of their lower biomass yield. However, the stems contain a higher concentration of the insecticide and a smaller quantity of extraneous material (such as pigments and phenolics) which must be removed during the purification of the active compound or in the production of an enriched extract. It should be emphasized that our study was conducted with a restricted population of trees and that the observed results may not be representative of all $P$. indica populations throughout its range.

In summary, this study reveals that the 1 content of naturally growing $P$. indica does not vary with season and it is not affected by either the nutritional status of the plant (nitrogen content) or the phenolic content. It does vary, however, among individual trees and is found to accumulate in the stems. We believe that this preliminary work provides information which could prove useful in the future utilization of this plant as a natural source of 1 .

\section{EXPERIMENTAL}

Plant samples. Two P. indica (Lauraceae) groups consisting of 10 mature trees randomly selected based on their size (height $\mathrm{ca} 15 \mathrm{~m}$ ) were established in 'Garajonay National Park' located on the island of La Gomera in the Canarian Archipelago. Groups 1 and 2 were $20 \mathrm{~km}$ apart, shared similar climatic conditions and were located at an altitude of $900 \mathrm{~m}$. The maximum annua! rainfall occurs between the months of November and February, and is followed by a growth period (mid-March-mid-August with maximum growth occurring between May and June, A. Fernández López, personal communication).

The samples were collected during the 2 growth periods included in this study $(4 / 89,7 / 89$ and $4 / 90$ plus $10 / 89$ as an intermediate date; $7 / 90$ was included in the quantification of 1 and nitrogen) and consisted of the pooled leaves from 3 terminal twigs $(20 \mathrm{~cm}$ average length) collected from marked branches at a height of $2 \mathrm{~m}$.

The plant samples collected were immediately placed in sealed plastic bags and deposited in an ice cooler to be weighed in the laboratory within $24 \mathrm{hr}$. The $\mathrm{H}_{2} \mathrm{O}$ content was calcd gravimetrically after oven-drying the samples for $48 \mathrm{hr}$ at $60^{\circ}$. The dried samples were pooled and ground in a Wiley mill to pass through a $2 \mathrm{~mm}$ sieve.

Plant extracts. Weighed amounts of dried ground samples (average of $2 \mathrm{~g}$ ) were extracted with $E t O H$ for $24 \mathrm{hr}$ in a Soxhlet. The extract was filtered and concd under low pres.

Chemical analysis. The $\mathbf{N}_{2}$ content of the tissue was measured using a Kjehldal digester equipped with a colorimetric autoanalyser. Compound 1 was quantified 
in duplicate by reverse-phase HPLC as previously described in ref. [5]. The total phenolic content was colorimetrically estimated in duplicate using the method of ref. [22] on 10- $\mu \mathrm{l}$ aliquots obtained from the previous extracts resuspended in $20 \mathrm{ml}$ of EtOH. Transcinnamic, caffeic and ferulic acids were used to generate a standard curve for the quantification.

For the comparison between leaves and stems, 3 twigs were collected from branches other than the marked ones from trees number $1,3,5,7$ and 9 at the beginning of the experiment (4/89). For each sample the 3 twigs were pooled and their leaves and stems separated for the chemical and nutritional analysis.

Statistical analysis. The parameters measured were analysed with the non-parametric Kruskall-Wallis one way ANOVA by ranks. The association between the variables was analysed with the non-parametric Spearman Rank correlation procedure. The coefficient $(\rho)$ varies between -1 (perfect negative correlation), 0 (no correlation) and 1 (perfect positive correlation). The null hypothesis assumes that the parent population has a correlation coefficient other than zero and the significance level $(P)$ is the probability that if the null hypothesis is true, then a coefficient as large or larger than the one calculated could come from a random sample.

Acknowiedgements - We gratefully acknowledge A. Fernández, Director of Garajonay National Park (ICONA) for his constant support. We also thank M. J. Contreras and the Park Rangers for their assistance in plant collection, S. Carlin for editing the English language and P. Escoubas for his constructive comments.

\section{REFERENCES}

1. González-Coloma, A., Hernández, G. M., Perales, A. and Fragá, B. M. (1990) J. Chem. Ecol. 16, 2723.

2. Waterhouse, A. L., Pessah, I. N., Francini, A. O. and Casida, J. E. (1987) J. Med. Chem. 30, 710.

3. Pessah, I. N. (1989) in Recent Advances in the Chemistry of Insect Control II (Crombie, L., ed.), pp. 278. Royal Society of Chemistry, London.
4. Jefferies, P. R., Toia, R. F., Brahnigan, B., Pessah, I. and Casida, J. E. (1992) J. Agric. Food Chem 40, 142.

5. González-Coloma, A., Cabrera, R., Castañera, P., Gutierrez, C. and Fraga, B. M. (1992) Phytechemistry 31. 1549.

6. Kefeli, V. I. and Kutace, K. M. (1976) in Plant Growth Regulation, Proceedings, 9th International Conference (Pilet, P. E., ed.), pp. 181. Springer, Berlin.

7. Jacobs, M. and Rubery, P. (1988) Science 24I, 346.

8. Rhodes, M. J. C. (1985) A. Proc. Phytochem. Soc. Euro. 25, 99.

9. Barry, T. N. and Manley, T. R. (1986) J. Sci. Food Agric. 37, 248.

10. Briggs, M. A. (1990) J. Chem. Ecol. 16, 1557.

11. Dustin, C. A. and Cooper-Driver, G. A. (1992) Biochem. Syst. Ecol. $20,99$.

12. Schultz, J. C., Nothnagle, P. J. and Baldwin, I. T. (1982) Am. J. Bot. 69, 753.

13. Denno, R. and McClure, M. (1983) Variable Plants and Herbivores in Natural and Managed Systems. Academic Press, New York.

14. Baldwin, I. T., Schultz, J. C. and Ward, D. (1987) J. Chem. Ecol. 13, 1069.

15. Lindroth, R. L., Hsia, M. T. S. and Scriber, J. M. (1987) Biochem. Syst. Ecol. 15, 681.

16. Cates, R. G. and Redak, R. A. (1988) in Chemical Mediation of Coevolution (Spencer, K. C., ed.), pp. 317. Academic Press, New York.

17. Gonnet, J. F. and Daniere, C. (1989) Biochem. Syst. Ecol. 17, 239.

18. Kelsey, R. and Vance, N. C. (1992) J. Nat. Prod. 55, 912.

19. Tan, S. C. (1980) Aust. J. Plant Physiol, 7, 159.

20. Bryant, J. P., Tuomi, J. and Niemala, P. (1989) in Chemical Mediation of Coevolution (Spencer, D. C., ed.), pp. 367. Academic Press, New York.

21. Flesch, V., Jacques, M., Cosson, L., Teng, B. P., Petiard, V. and Balz, J. P. (1992) Phytochemistry 31, 1941.

22. Julkunen-Tiito, R. (1985) J. Agric. Food Chem. 33, 213. 